\title{
Management Options for Improving Flowering in Citrus Production ${ }^{1}$
}

\author{
Leigh Archer, Miurel Brewer, Bikash Adhikari, Eduardo Esteves, Christopher Vincent, and Tripti \\ Vashisth $^{2}$
}

\section{Introduction}

The final fruit yield and, ultimately, returns a grower receives from any given harvest are directly related to the number of viable flowers that are generated and the proportion of those flowers that produce fruit. Citrus breeding programs and the use of mature budwood in grafting help eliminate the relatively lengthy juvenility period typical in citrus, reducing the number of years before a tree produces flowers. Once a tree reaches its fruit-bearing age, multiple environmental and cultural components impact the number and viability of flowers produced each year.

Our continually expanding knowledge base on floral regulation has allowed us to understand the physiological aspects of citrus flowering, such as juvenility and alternate bearing. Flowering is a multistep process in which a plant transitions from vegetative to reproductive production (Nishikawa 2013). A grower can improve the ability for their trees to consistently produce a profitable crop of fruit by understanding the steps involved in flowering and controlling the transition to reproductive growth.

Floral induction is a process that can be described as a physiological switch allowing a developing bud to produce flowers. This is distinct from the process of floral initiation, which is the irreversible process that starts the growth of a flower. In humid subtropical climates, the typical climate for most of Florida's production zones, temperature is the driving force behind flowering. Temperatures must drop low enough for a long enough period to initiate flowering, though there is no single threshold of hours associated with flowering. Rather, increasing exposure to cool temperatures induces more intense flowering. In Florida, floral initiation is highly dependent on cold temperatures ranging from $59^{\circ} \mathrm{F}$ to $68^{\circ} \mathrm{F}$ in the fall and winter (Nishikawa 2013). The flowering process in citrus is primarily induced by cold temperatures or by drought stress, depending on the climate where it is being grown. Floral development is directly related to the length and intensity of cold temperatures and drought. However, if either of these factors is insufficient or cannot be easily controlled, there are alternatives for ensuring adequate and consistent flowering.

In an era of both changing climatic conditions and huanglongbing (HLB), Florida growers are experiencing added challenges related to flower load and off-season flowering. Ongoing research will continue to explore options for controlling the floral disruptions associated with HLB; in the meantime, growers can take steps toward mitigating poor fruit set by considering how effectively their trees are producing viable flowers. Managing water

1. This document is HS1399, one of a series of the Horticultural Sciences Department, UF/IFAS Extension. Original publication date December 2020. Visit the EDIS website at https://edis.ifas.ufl.edu for the currently supported version of this publication.

2. Leigh Archer, graduate research assistant, Horticultural Sciences Department, UF/IFAS Southwest Florida Research and Education Center, Immokalee FL; Miurel Brewer, graduate student, Department of Soil and Water Sciences; Bikash Adhikari, graduate student, Horticultural Sciences Department; Eduardo Esteves, graduate student, Department of Soil and Water Sciences; Christopher Vincent, assistant professor, Horticultural Sciences Department; and Tripti Vashisth, assistant professor, Horticultural Sciences Department, UF/IFAS Citrus REC, Lake Alfred, FL 33850.

The Institute of Food and Agricultural Sciences (IFAS) is an Equal Opportunity Institution authorized to provide research, educational information and other services

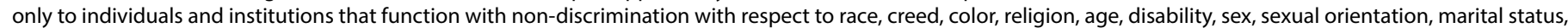

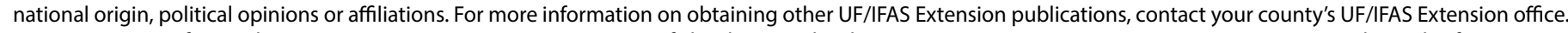
U.S. Department of Agriculture, UF/IFAS Extension Service, University of Florida, IFAS, Florida A \& M University Cooperative Extension Program, and Boards of County Commissioners Cooperating. Nick T. Place, dean for UF/IFAS Extension. 
stress, understanding the carbohydrate status of a tree, and utilizing chemical or hormone applications are all options for growers. In both commercial and backyard settings, these techniques can be employed to improve flowering and increase yield. These options are described in this article and should be considered as part of an integrated management plan to address low or irregular yields due to insufficient flowering or fruit set.

\section{Water Management}

Although temperature is a key component for maximizing yield, it is practically impossible for growers to regulate it. Growers in subtropical regions can naturally rely on temperatures to induce flowering, but unpredictability in weather patterns can cause irregular flowering. In tropical climates, where temperatures rarely dip low enough, water stress is the key factor controlling floral induction (Davies 1997). To ensure even and consistent fruit set, growers in the subtropics can also induce flowering by managing irrigation.

Water stress requirements and responses are specific for different varieties and climates. The length and severity of the drought that should be implemented to begin flower induction is highly dependent on regional temperatures, soil conditions, cultivar, and the previous year's crop load. Typically, at least 60 days of drought are needed for flower induction in subtropical regions like Florida, though it may only take 45 to 60 days in tropical areas (Albrigo et al. 2019).

Floral development may begin as soon as 7 to 10 days after an irrigation event ending the water deficit period, though in some regions, flowering may not start until four weeks after an irrigation event (Albrigo et al. 2019). In lemon, an additional benefit of managing water deficit is the ability to extend the harvest season. In Italy, lemons typically flower in spring and are harvested in October of the same year. To induce an earlier harvest, growers have successfully implemented water stress during the summer, the Forzatura technique, to produce lemons that are harvested early during the following summer (Albrigo et al. 2019). In general, the managed water stress method is effective across Italy and other growing zones with Mediterranean climates characterized by very little rain during the summer. In Florida, rainfall is mostly distributed during the summer and fall, which makes inducing drought stress more challenging during this time, though it is practicable during the dry season.
Careful irrigation scheduling is important; extended drought periods can cause fruit drop, leaf drop, root damage, and flower abortion. The severity of water stress that is needed for floral induction without damaging trees is variable, and different methodologies for inducing stress are still being tested.

Recent studies found that applying irrigation at $50 \%$ of crop demand resulted in the same level of floral induction as with no irrigation (Albrigo and Carrera 2015). For those specific conditions, water stress induction was achieved without causing severe water stress damage to trees. A similar technique, termed Moderate Drought Stress Management System (MDSM) (Albrigo and Carrera 2015), promotes flower induction with an ultralow irrigation schedule. This keeps plants in a nongrowing condition but reduces the adverse effects of severe water stress.

In Florida's subtropical climate, the option to apply drought stress may help to increase floral development. In the era of endemic HLB, however, promoting severe drought stress may drastically increase fruit drop. Due to extensive root damage, HLB-infected trees are prone to drought stress even when well watered, leading to irregular and off-season flowering as well as increased fruit drop throughout the year. It is critical to carefully consider the benefits and risks associated with water stress when applied to trees that are already enduring significant disease pressure.

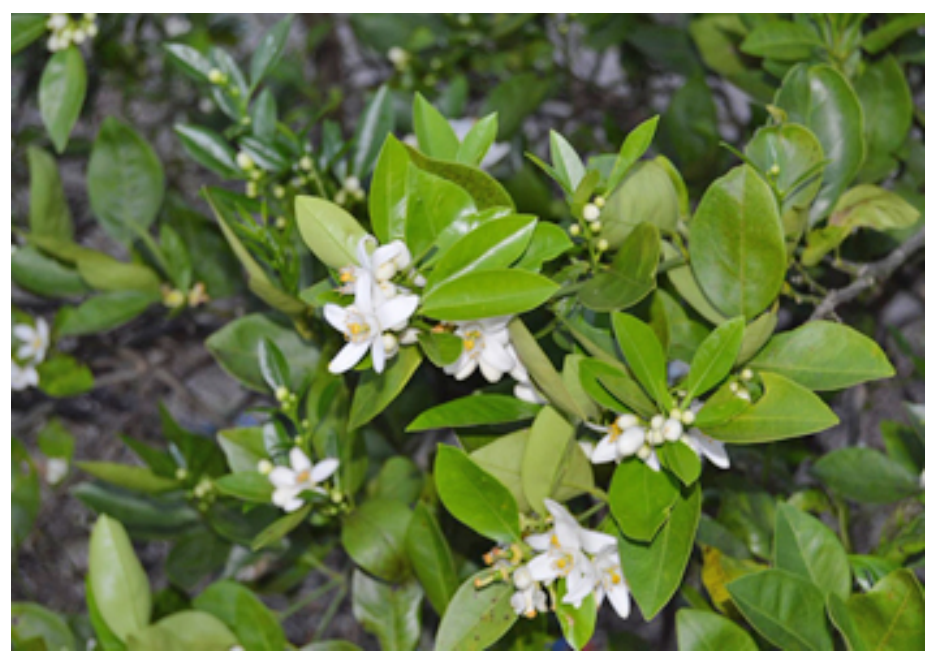

Figure 1. Hamlin variety oranges flowering.

Credits: Miurel Brewer, UF/IFAS

\section{Carbohydrate Status}

Developing fruits are the strongest competitors for a tree's available energy resources. The presence of fruit can prevent the accumulation of reserves in other parts of the tree and inhibits flower formation and development (Goldschmidt 1999). When fruit development overlaps with flowering, developing flowers are unable to access 
enough carbohydrates to remain viable. As a result, these flowers may drop in a process known as bud abscission. At the whole-plant level, fruit can also directly influence the behavior of a bud by reducing the number of flowers formed at each available flower-forming node.

Citrus flowers profusely; less than $2 \%$ of the flowers make up the harvestable crop. Abscission of buds and flowers is a common natural process in trees. Dropping excess buds and flowers helps to conserve energy reserves in the tree because a tree is generally unable to supply the necessary carbohydrates to support every flower that it produces (Goldschmidt 1999). The availability of carbohydrates depends on the amount stored in tree organs, such as stems and roots, and the amount being generated by the plant through photosynthesis. 'Murcott' tangerines are highly susceptible to carbohydrate starvation in the roots, and subsequent whole-tree decline can occur after several consecutive heavy cropping years, a phenomenon aptly named "Murcott collapse." In addition to the physiological effects of carbohydrate competition, excess fruit load can cause limb breakage and structural damage to branches.

Fully developed leaves will accumulate carbohydrates from the time new flush sprouts until bloom. After bloom, the amount of carbohydrates in these leaves will generally decline until the end of flower and fruitlet abscission. Although there are a variety of plant hormonal signals that initiate and carry out flower and fruitlet abscission, these signals are likely related to carbohydrate availability. Any disease or other management factor that causes leaf loss can contribute to a loss of carbohydrate uptake capability. Freeze injury, greasy spot, and mite problems can all contribute to leaf loss, particularly in the fall, and will contribute to a reduction in carbohydrate availability, thus contributing to floral abscission.

In addition to disease and environmental factors contributing to the reduction in carbohydrate availability, individual shoots with heavy fruit loads one year will generally not flower and produce fruit the following year. The available carbohydrate within a branch becomes limited, and fruits will outcompete developing flowers for an energy source. Alternate bearing occurs when a heavy crop load year is followed by a very light yield. There is a tendency for this phenomenon to synchronize across an orchard, which can be highly disruptive to commercial practices and can be economically damaging to both fresh and processing citrus producers (Nishikawa 2013). Alternate bearing is heavily dependent on the fruit type and cultivar, with certain mandarin types being particularly susceptible. Management options for limiting the likelihood of this phenomenon do exist and primarily involve thinning and pruning.

Thinning-Citrus trees may set more fruit than what can develop adequately. Growers may choose to selectively remove a portion of the fruiting shoots or immature fruits during the spring. Thinning is particularly useful when there is a heavy crop load, which may increase the likelihood of alternate bearing the following year, or when greater fruit size and quality are important for existing crop. Early-season selective harvest or removal of a portion of the crop can also help minimize the risks associated with a late-harvested variety. The cultivar 'Valencia', for example, may not be harvested until after flowering and fruitlet development of the next crop. This competition for carbohydrates between flowers and fruit can increase the degree of floral and fruitlet abscission and thus reduce the subsequent year's crop. In general, reducing the length of time fruit are held on the tree can help to minimize risks of carbohydrate competition and floral abscission.

Pruning-The most common practice growers use to reduce excessive flowering is pruning. This is important for controlling tree shape and height, removing unhealthy branches, and increasing light penetration in the canopy. Most recommendations suggest pruning in the late winter or early spring; however, the best time of year depends on climate, variety, and management history. Pruning after a heavy crop will exacerbate the problem of alternate bearing and cause increased vegetative growth the following year. Pruning after a light crop, in the season before an expected heavy crop, can reduce this imbalance and allow for more even crop loads (Tucker et al. 1994). Mechanical hedging is the most common technique to reduce crowding within a grove. Hedging programs can vary drastically depending on the variety, spacing, equipment, and costs. A hedging program should be individually tailored for each orchard.

Some hedging programs call for years of intense pruning on certain sides or rows in an orchard. Heavy pruning may cause a reduction in carbohydrates because there are fewer leaves available for active production. Trees with excess nitrogen available after heavy pruning may respond with vigorous vegetative growth and low fruit production. Reducing applications of nitrogen fertilizer after heavy pruning can help to minimize the risk of this imbalance. Topping trees at a single height is another practice that can help increase light penetration into trees. Techniques that stimulate photosynthesis can contribute to the overall carbohydrate reserves and increase bud strength to minimize abscission (Tucker et al. 1994). 


\section{Chemical and Hormone Applications}

Balanced mineral nutrition is critical for healthy and timely flowering. If a single element is deficient, aspects of floral development can be hampered, even if other elements are available at their optimum levels. Detailed information on citrus nutrition is available online from the UF/ IFAS Citrus Tree Nutrient series (http://edis.ifas.ufl.edu/ topic_series_citrus_tree_nutrients).

HLB, which is widespread in Florida, inhibits root function, leading to various macro- and micronutrient deficiencies and affecting flowering and fruit development. The UF/ IFAS book Nutrition of Florida Citrus Trees now has HLBrelated nutrition updates in every chapter (https://edis.ifas. ufl.edu/ss478).

Phosphorous $(\mathrm{P})$ is a critical nutrient for flowering. $\mathrm{P}$ deficiencies can cause limited flower development, reduced fruit set, and yield losses. $\mathrm{P}$ application rates and concentrations should follow established guidelines based on foliar analyses and should be individualized for soil type, cultivar, and environmental conditions. Poor flower development and limited fruit set are often symptoms used to diagnosis $\mathrm{P}$ deficiencies. $\mathrm{P}$ deficiency can readily occur in sandy soils with humid climates. It can become unavailable through fixation and immobilization by other soil elements, such as iron, aluminum, and calcium. $\mathrm{P}$ is relatively stable in high $\mathrm{pH}$ soils (>6). Under these conditions, regular P fertilization is typically unnecessary. Where it is required, both soil and foliar application of P fertilizer are utilized. Soilapplied sources commonly used in Florida groves include superphosphates, monoammonium phosphate (MAP), and diammonium phosphate (DAP). P sources applied through foliar sprays include potassium phosphite, ammonium phosphite, and phosphorous acid.

Most of these fertilizers supply $\mathrm{P}$ in the form of neutralized phosphoric acid $\left(\mathrm{H}_{3} \mathrm{PO}_{4}\right)$ (Zekri and Obreza 2009). Phosphite, which is the compound formed from neutralized phosphorous acid $\left(\mathrm{H}_{3} \mathrm{PO}_{3}\right)$, is readily absorbed by citrus leaves and can accelerate the foliar uptake of other nutrients, but it does not contribute to phosphate nutrition (Lovatt and Mikkelsen 2006). In deficient plants, foliar applications of phosphite can increase citrus floral intensity, yield, fruit size, total soluble solids, and anthocyanin content. However, with the application of many foliar sprays, phytotoxicity is a frequent problem when the dose or concentration is not correctly formulated.
Nitrogen $(\mathrm{N})$ is an important nutrient for floral development, fruit production, and tree growth. High levels of $\mathrm{N}$ may cause increases in vegetative growth instead of floral development. $\mathrm{N}$ fertilizer can be applied to the soil or through foliar sprays, and it often relies on urea as a source. Studies indicate that high levels of $\mathrm{N}$ in the buds and leaves obtained by winter applications of urea along with flowering-enhancing environmental cues can increase the number of flowers per tree, and $\mathrm{N}$ fertilization, in general, can improve canopy width and flower yield (Lovatt et al. 1988; Albrigo 1999). N deficiency is generally characterized by yellowing foliage, which is most prevalent after flowering and before the summer rainy season.

Severe deficiencies of almost all other nutritional elements can ultimately lead to poor floral development. Integrated nutrient management systems based on foliar nutritional analyses should be an important first step in promoting floral development (Zekri and Obreza 2009).

In addition to nutritional elements, multiple hormones produced by the tree are involved in flowering. Gibberellins (GA) tend to inhibit flowering in many fruit trees, whereas they generally promote flowering in herbaceous plants. In citrus, high levels of GA in the fall can inhibit floral induction and reduce the number of buds that form in the spring. Applications of GA are typically used to delay fruit senescence but can be utilized by growers who are looking to reduce fruit set if excessive crop load is expected (Garmendia et al. 2019). The timing of GA applications is particularly important to avoid unintended losses in fruit set and yield.

Auxins are used as a method for thinning excessive crop load. Cytokinins, on the other hand, stimulate cell division and counteract the apical dominance induced by auxins. Endogenous cytokinin in buds increases at the onset of floral differentiation in citrus. Applications of this hormone could play a role in breaking bud dormancy and promoting floral induction. Ethylene plays a major role in leaf, flower, and fruit abscission. Excessive ethylene production due to a pathogen infection during bloom can result in abscission of flower and fruitlet, such as in cases of postbloom fruit drop.

Tree response to the application of hormones depends upon overall plant health and nutrition, levels of existing hormones within the tree, tree phenology, concentration applied, and time of application. When properly formulated and timed, applications of these compounds can be powerful tools used for manipulating tree growth, flowering, and yield. 
CAUTION: Plant growth regulators may cause phytotoxicity, yield loss, and unusual results if not applied at the suggested rate or time. Additional recommendations can be found in the Florida Citrus Production Guide chapter Plant Growth Regulators (https://edis.ifas.ufl.edu/hs1310).

\section{Conclusion}

Flower management is a key component in determining the final fruit yield in many tree crops, including citrus. Floral induction and floral initiation are two distinct processes that contribute to a tree's ability to produce a profitable and uniform crop every year. These processes are directly impacted by environmental factors such as temperature, disease pressure, and cultural management choices. Consideration of the carbohydrates available for maturing fruits and developing flowers can help to limit the extent of floral abscission related to insufficient carbohydrates. Proper pruning and thinning can help to mitigate the intensity of alternate bearing to allow for a steady crop load each year. Maximizing light interception and penetration, reducing floral or fruitlet load appropriately, and applying nitrogen fertilizers to reduce an imbalance between vegetative and reproductive growth are all strategies that can help maintain an appropriate carbohydrate status. Promoting floral induction through water stress management is an option for growers, but one should carefully consider the benefits and risks thereof in the era of endemic HLB. Nutrient management and the application of hormones are additional techniques for growers who are struggling with adequate floral load and set each year. Any application of chemicals or hormones should be considered in the context of a well-developed integrated management plan.

Management practices appropriate for anthesis and pollination were not discussed in this article; however, these are presented in-depth in other articles, such as Cross-Pollination Planting Plans (https://edis.ifas.ufl.edu/ ch070) or Pollination of Citrus Hybrids (https://edis.ifas.ufl. edu/ch082). Efficient pollination is as critical to maximizing production as floral regulation.

Although certain aspects of flowering can be managed, before planting a new orchard, it is imperative to choose varieties appropriate for the climate where they will be grown. In an era of climate unpredictability, knowing the variety to plant that will be successful in the future is challenging. The Florida Citrus Production Guide provides up-to-date information on how to plan and plant a new orchard and is available online at https://crec.ifas.ufl.edu/resources/ production-guide/. Even the most intensive management cannot overcome poor-producing trees if they are being grown in an inappropriate climate. As with crop production in any region, careful consideration of weather and other external factors before implementing any management plan is important.

\section{Additional Information}

The 2020-2021 Florida Citrus Production Guide: https://

crec.ifas.ufl.edu/resources/production-guide/\#hort

The University of California Citrus Production Manual: https://anrcatalog.ucanr.edu/Details.aspx?itemNo=3539

The UF/IFAS EDIS website offers a range of recommendations for citrus production by researchers and other experts: https://edis.ifas.ufl.edu/topic_citrus

"Plant Growth Regulators for Citrus Production": http:// ipm.ucanr.edu/PMG/r107900111.html

\section{References}

Albrigo, L. G. 1999. "Effects of Foliar Applications of Urea or Nutriphite on Flowering and Yields of Valencia Orange Trees." Proc. Fla. State. Hort. Soc. 112:1-4.

Albrigo, L. G., and R. R. Carrera. 2015. "Managing Drought Stress of Oranges under Sao Paulo-Mina Gerais, Brazil Conditions to Optimize Flower Bud Induction and Productivity." Acta Horticulturae 1065:1251-1256. https://doi. org/10.17660/ActaHortic.2015.1065.159

Albrigo, L. G., L. L. Stelinski, and L. W. Timmer. 2019. Citrus. 2nd ed. CABI.

Davies, F. S. 1997. "An Overview of Climatic Effects on Citrus Flowering and Fruit Quality in Various Parts of the World." UF/IFAS Citrus Flowering Short Course 1997.

Garmendia, A., R. Beltrán, C. Zornoza, F. J. García-Breijo, J. Reig, and H. Merle. 2019. "Gibberellic Acid in Citrus spp. Flowering and Fruiting: A Systematic Review." PLoS ONE 14 (9): e0223147.

Goldschmidt, E. E. 1999. "Carbohydrate Supply as a Critical Factor for Citrus Fruit Development and Productivity."

HortSci. 34 (6): 1020-1024.

Lovatt, C. J., and R. L. Mikkelsen. 2006. "Phosphite Fertilizers: What Are They? Can You Use Them? What Can They Do?" Better Crops 90 (4): 11-13. 
Lovatt, C. J., Y. Zheng, and K. D. Hake. 1988. "Demonstration of a Change in Nitrogen Metabolism Influencing Flower Initiation in Citrus." Israel J. of Botany 37 (2-4): 181-188.

Nishikawa, F. 2013. "Regulation of Floral Induction in Citrus." J. of Japan Soc. of Hort. Sci. 82:283-292.

Tucker, D. P. H., T. A. Wheaton, and R. P. Muraro. 1994. Citrus Tree Pruning Principles and Practices. HS144. Archived. Gainesville: University of Florida Institute of Food and Agricultural Sciences.

Vashisth, T., C. Oswalt, M. Zekri, F. Alferez, and J. D. Burrow. 2020. 2020-2021 Florida Citrus Production Guide: Plant Growth Regulators. CMG17. Gainesville: University of Florida Institute of Food and Agricultural Sciences. https:// edis.ifas.ufl.edu/hs1310

Zekri, M., and T. A. Obreza. Rev. 2009. Plant Nutrients for Citrus Trees. SL 200. Gainesville: University of Florida Institute of Food and Agricultural Sciences. https://edis.ifas. ufl.edu/ss419 